\title{
Soja associada à inoculação e coinoculação de Bradyrhizobium e Azospirillum após cultivos de outono-inverno
}

\author{
Darlan Souza Flauzino ${ }^{1}$, Luan Marlon Ribeiro², Gessí Ceccon³ \\ ${ }^{1}$ Serviço Nacional de Aprendizagem Rural - Senar, MS, Dourados, MS, Brasil. E-mail: darlan_souza_93@hotmail.com \\ ${ }^{2}$ Universidade Federal da Grande Dourados - UFGD, Dourados, MS, Brasil. E-mail: luanmarlon@ hotmail.com \\ ${ }^{3}$ Empresa Brasileira de Pesquisa Agropecuária - Embrapa Agropecuária Oeste - CPAO, Dourados - MS, Brasil. E-mail: \\ gessi.ceccon@embrapa.br
}

Recebido: 19/08/2017; Aceito: 08/02/2018.

\begin{abstract}
RESUMO
Objetivou-se avaliar o desenvolvimento e os componentes de produção da cultura da soja com e sem inoculação de Bradyrhizobium japonicum, e a coinoculação de B. japonicum mais Azospirillum brasilense após cultivos de outono-inverno. O delineamento experimental foi em blocos casualizados, com parcelas subdivididas. As parcelas principais foram os cultivos de outono-inverno (feijão-caupi, Brachiaria ruziziensis, milho solteiro e consórcio de milho-B. ruziziensis), e nas subparcelas a soja BRS 360 RR, sem inoculação (BRS 360-0), inoculada com $B$. japonicum (BRS 360-CB) e a coinoculação com B. japonicum + A. brasilense (BRS 360-CB+A), em quatro repetições. Os dados foram submetidos à análise de variância e as médias comparadas pelo teste de Tukey $(\mathrm{p}<0,05)$. Não houve diferença no rendimento de massa de plantas verdes e número de grãos por planta. A soja sem inoculante após milho solteiro apresentou maior produtividade $\left(2.573 \mathrm{~kg} \mathrm{ha}^{-1}\right)$ com incrementos no índice de área foliar $\left(5,4 \mathrm{~m}^{2}\right)$; quando inoculada com B. japonicum; com a coinoculação de B. japonicum mais A. brasilense observou-se maior produtividade após milho solteiro $\left(2.737 \mathrm{~kg} \mathrm{ha}^{-1}\right)$ e consórcio de milho com $B$. ruziziensis (2.511 $\left.\mathrm{kg} \mathrm{ha}^{-1}\right)$. Os cultivos de outono-inverno que possuem a presença de milho proporcionam maior produtividade da cultura com ou sem a inoculação.
\end{abstract}

Palavras-chave: Glycine max (L.), sucessão de culturas, plantio direto.

\section{Soybean associated to inoculation and co-inoculation of Bradyrhizobium and Azospirillum after autumn-winter crops}

\begin{abstract}
The objective of this study was to evaluate the development and productivity components of soy with and without inoculation of Bradyrhizobium japonicum and the co-inoculation of B. japonicum and Azospirillum brasilense after autumn-winter crops. The experimental design was in randomized blocks, with subdivided plots. The main plots were autumn-winter crops (Cowpea, Brachiaria ruziziensis, single corn and corn intercropping with $B$. ruziziensis), and in the subplots BRS 360 RR cultivar, without inoculation (BRS 360-0), inoculated with $B$. japonicum (BRS 360-CB) and co-inoculation with B. japonicum + A. brasilense (BRS 360-CB+A), in four replicates. The data were submitted to analysis and the means were compared by the Tukey test ( $p<0.05)$. There was no difference in the yield of green plants and number of grains per plant. The soy no-inoculated after single corn showed higher yield $\left(2,573 \mathrm{~kg} \mathrm{ha}^{-1}\right)$ with increases in leaf area index $\left(5.4 \mathrm{~m}^{2}\right)$; and corn intercropping with $B$. ruziziensis $\left(2,511 \mathrm{~kg} \mathrm{ha}^{-1}\right)$ were observed to be higher when $B$. japonicum was inoculated with $B$. japonicum and A. brasilense. Autumn-winter crops with corn provide higher crop productivity inoculated not.
\end{abstract}

Key words: Glycine max (L.), crop succession, no-tillage. 


\section{Introdução}

O Brasil possui elevado potencial de produção de grãos, sendo esta uma das principais atividades econômicas da região Centro-Oeste. Em Mato Grosso do Sul predomina a sucessão soja-milho safrinha (PADOVAN et al., 2013). Embora seja rentável, existem outros cultivos de outono-inverno de grande importância que podem ser utilizados em sucessão com a soja. Somente o sistema contínuo de sucessão sojamilho safrinha tende a provocar a degradação dos componentes do solo e consequente queda na produtividade, além de proporcionar condições favoráveis para a incidência de doenças, pragas e plantas daninhas. Deste modo, se faz necessária a introdução de outras espécies como forma de rotação de cultura, de preferência gramíneas (BUENO et al., 2014).

Esta alternância de culturas, ajuda na viabilização do sistema de plantio direto (SPD) e dos seus efeitos benéficos sobre a produção agropecuária e sobre o ambiente (BUENO et al., 2014), visando a conservação, manutenção da umidade, melhorias na estrutura física e química do solo, maior acúmulo de matéria orgânica e resposta das culturas sobre esse sistema (CHIODEROLI et al., 2010). Como opção, apresenta-se o feijão-caupi (Vigna unguiculata (L.) Walp.), por ser uma espécie que possibilita boa cobertura e melhor fertilidade do solo (FREIRE FILHO et al., 2005); suas características como a rusticidade, ciclo curto, comportamento de adubo verde e constitui como importante espécie para cultivo no outono-inverno em Mato Grosso do Sul (LOCATELLI et al., 2016).

Outra opção é a Brachiaria ruziziensis em cultivo solteiro ou consorciado com milho proporcionando maior estabilidade produtiva das culturas em sucessão pela ciclagem de nutrientes e conservação do solo (COSTA et al., 2012); quanto mais tardia for realizada a dessecação da forrageira, maior será a quantidade de palha sobre o solo e, consequentemente, melhores serão as condições para cultivo da soja em sucessão (CECCON et al., 2013).

Com o crescimento da produção e o aumento da capacidade competitiva da soja, são necessários outros incrementos de avanços científicos além dos cultivos de outono inverno, como o desenvolvimento de inoculantes com estirpes de bactérias fixadoras, ou seja, a fixação biológica de nitrogênio (FBN) (MERCANTE et al., 2011). Embora o nitrogênio seja o mais abundante dos elementos do ar atmosférico, as plantas não são capazes de metaboliza-lo na forma gasosa e retirá-lo diretamente do ar, necessitando do auxílio de bactérias fixadoras de nitrogênio (MYLONA et al., 1995). A utilização dessas bactérias é uma das formas de reduzir o uso de insumos, especialmente o nitrogênio, como forma de otimizar sua disponibilidade para as plantas (MERCANTE et al.,
2011); elas são de baixo custo e têm sido estudadas com o objetivo de aumentar a produtividade das culturas (BASHAN et al., 2014).

Outra técnica alternativa é a coinoculação ou inoculação mista, que consiste na utilização de diferentes microrganismos ao mesmo tempo, os quais produzem um efeito sinérgico a fim de superar resultados quando testados isoladamente (FERLINI, 2006). Dentre as bactérias do solo, as espécies Bradyrhizobium japonicum e do gênero Azospirillum têm sido extremamente importantes para a cultura da soja pois estabelecem uma relação extremamente harmônica (simbiose) com as plantas (KUMUDINI, 2010)

Deste modo, objetivou-se avaliar o desenvolvimento e componentes de produtividade da soja com e sem inoculação de Bradyrhizobium japonicum e a coinoculação de Bradyrhizobium japonicum mais Azospirillum brasilense, em sucessão aos cultivos de outono-inverno, nas condições de Dourados, MS.

\section{Material e Métodos}

O experimento foi realizado no ano agrícola 2014/15, na área experimental da Embrapa Agropecuária Oeste, localizado no município de Dourados-MS, coordenadas $22^{\circ} 13^{\prime}$ latitude Sul e $54^{\circ}$ 48' longitude Oeste, aproximadamente $595 \mathrm{~m}$ de altitude. O solo é classificado como Latossolo Vermelho Distroférrico de textura muito argilosa (SANTOS et al., 2013). A análise química do solo na camada $0-0,20 \mathrm{~m}$ apresentou os seguintes resultados: $\mathrm{pH}\left(\mathrm{CaCl}_{2} 0,01 \mathrm{ml}^{-1}\right)$ $=6,2 ; \mathrm{V}=79,3 \%$; M.O $\left(\mathrm{g} \mathrm{kg}^{-1}\right)=37,9 ; \mathrm{P}\left(\mathrm{mg} \mathrm{dm}^{-3}\right)=$ 57,$3 ; \mathrm{K}\left(\mathrm{cmol}_{\mathrm{c}} \mathrm{dm}^{-3}\right)=1,0 ; \mathrm{Ca}\left(\mathrm{cmol}_{\mathrm{c}} \mathrm{dm}^{-3}\right)=6,5 ; \mathrm{Mg}$ $\left(\mathrm{cmol}_{\mathrm{c}} \mathrm{dm}^{-3}\right)=2,8$ e $\mathrm{Al}\left(\mathrm{cmol}_{\mathrm{c}} \mathrm{dm}^{-3}\right)=2,7$.

O clima de Dourados, segundo a classificação de Köppen, é do tipo Am (Tropical Monçônico), com verões quentes e invernos secos, temperaturas máximas observadas nos meses de dezembro e janeiro e temperaturas mínimas entre maio e agosto, coincidindo com chuvas excedentes na primavera - verão e déficit hídrico no outono-inverno (FLUMIGNAN et al., 2015).

A área experimental é manejada em Plantio Direto há 15 anos, num esquema de sucessão de culturas há sete anos; no outono-inverno é cultivado feijão-caupi (var. guariba), milho safrinha, Brachiaria ruziziensis e consórcio de milho com B. ruziziensis, no verão é cultivada a soja.

$\mathrm{O}$ delineamento experimental utilizado foi em blocos casualizados, com parcelas subdivididas. As parcelas principais foram compostas pelos quatro cultivos de outono-inverno (feijão-caupi, Brachiaria ruziziensis, milho solteiro, e consórcio de milho com $B$. ruziziensis) e nas subparcelas a cultivar de soja BRS 
360 RR, sem inoculação (BRS 360 - 0), inoculada com Bradyrhizobium japonicum (BRS 360 - CB) e a coinoculação com Bradyrhizobium japonicum + Azospirillum brasilense (BRS 360 - CB+A), com quatro repetições. A BRS 360 RR, é transgênica (tolerância ao herbicida glifosato, RR2 PRO TM), ciclo precoce, crescimento indeterminado, possui grupo de maturação 6.2 (EMBRAPA, 2013).

A dessecação da área foi realizada aos 15 dias antes da semeadura da soja, utilizando herbicida gliphosate na dose $1,08 \mathrm{~kg}$ e. a. ha ${ }^{-1}$ para supressão de plantas daninhas e braquiária dos cultivos de outono-inverno. A semeadura foi realizada mecanicamente em 09 de outubro de 2014, em sucessão aos cultivos de outonoinverno, utilizando semeadora modelo PAR 2800 regulada para distribuição $250 \mathrm{~kg} \mathrm{ha}^{-1}$ do formulado 0020-20 de NPK, na profundidade de $10 \mathrm{~cm}$, com população de 244.444 plantas $\mathrm{ha}^{-1}$.

As doses do inoculante à base de Bradyrhizobium japonicum utilizadas no ensaio foram: $100 \mathrm{ml} / 40 \mathrm{~kg}$ de sementes e $100 \mathrm{ml} / 50 \mathrm{~kg}$ de sementes para o inoculante à base de Azospirillum brasilense. Para o controle de insetos-pragas foi realizada uma aplicação de flubendiamida (120 mL i.a. ha $\left.{ }^{-1}\right)$ e para o controle de doenças foi realizada uma aplicação de trifloxistrobina e protioconazol (400 mL i.a. ha ${ }^{-1}$ ) em 11/1/2014.

Os dados de precipitação e temperaturas durante a condução do experimento no ano agrícola 2014/15 foram obtidos na Estação Meteorológica da Embrapa Agropecuária Oeste localizada a 300 m da área experimental. $\mathrm{O}$ total da precipitação no período experimental em 2014/15 foi de $517 \mathrm{~mm}$ (Figura 1). No dia 20 de novembro de 2014, quando as plantas estavam no estádio de florescimento $\left(\mathrm{R}_{2}\right)$, foram coletadas manualmente 5 plantas de cada parcela para a determinação de altura de plantas (AP), área foliar por planta (AFP), massa de folhas secas, massa de hastes secas e massa total seca (folhas + haste).

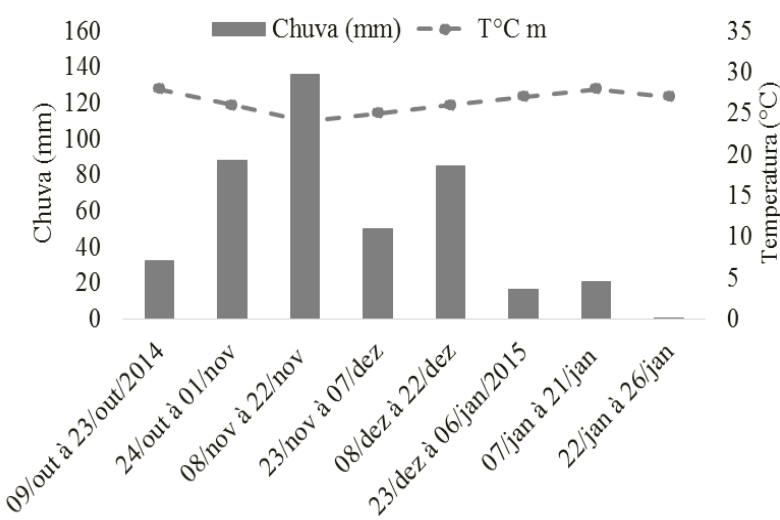

Figura 1. Valores quinzenal de chuvas e temperatura média registradas durante a condução do experimento no ano agrícola 2014/15, em Dourados-MS. Fonte: Embrapa, 2015.
A área foliar foi medida pelo aparelho medidor de área da marca LI-COR ${ }^{\circledR}$, modelo LI 3100, determinando a área foliar em $\mathrm{cm}^{2}$. O índice de área foliar (IAF) foi calculado pela relação entre a área foliar da planta e a área de solo ocupada. Também foi mensurado os índices de clorofila A, clorofila B e clorofila total, utilizando-se clorofilômetro eletrônico portátil do modelo CFL1030; as leituras foram realizadas pela manhã em três plantas por tratamento.

A massa de plantas secas foi obtida pela secagem em estufa com circulação de ar forçado a $60^{\circ} \mathrm{C}$ até peso constante, e rendimento de massa de folhas secas (RMFS), rendimento de massa de hastes secas (RMHS) e rendimento de massa de plantas secas total (RMST), foram estimados por $\mathrm{kg} \mathrm{ha}^{-1}$ com base na população final de plantas de soja.

A maturação fisiológica da soja ocorreu em 26 de janeiro de 2015, quando realizou-se a coleta das plantas em 2 linhas de $3 \mathrm{~m}$ de comprimento, espaçadas por 0,45 $\mathrm{m}$, utilizando-se colheitadeira de parcela (wintersteiger); após secagem total dos grãos determinou-se os componentes de produtividade, com correção da umidade para $13 \%$.

Os dados foram submetidos à análise de variância e quando detectada diferença significativa pelo teste $\mathrm{F}$, as médias foram comparadas pelo teste de Tukey $(\mathrm{p}<0,05)$.

\section{Resultados e Discussão}

Os resultados para altura de plantas (AP), clorofila A, clorofila B, clorofila total e massa de cem grãos (M100) não foram influenciados pela interação entre cultivos de outono-inverno e inoculação das bactérias avaliadas, mas foram significativos para o fator isolado de cultivos de outono-inverno (Tabela 1).

A soja apresentou maior AP quando cultivada em sucessão ao feijão-caupi, Brachiaria ruziziensis e consórcio de milho com B. ruziziensis. Cultivos como B. ruziziensis solteira ou consorciada com milho podem proporcionar maior estabilidade produtiva às culturas em sucessão pela ciclagem de nutrientes e conservação do solo devido ao grande aporte de resíduos vegetais sobre a superfície do mesmo (COSTA et al., 2012). O feijão-caupi, sendo leguminosa, contribui com a introdução de até $68 \mathrm{~kg} \mathrm{ha}^{-1}$ de $\mathrm{N}$ no solo através da fixação biológica de nitrogênio (CASTRO et al., 2004), o que pode explicar também os índices de clorofila A, B e total $(31,8,11,6$ e 43,4, respectivamente), sendo maiores quando houve o cultivo da soja em sucessão ao feijão-caupi. O mesmo foi observado por Oliveira et al. (2013), onde a sucessão feijão-comum/soja apresentou maior produção de matéria seca das plantas e maiores índices de área foliar. 
Tabela 1. Altura de plantas (AP), clorofila A (Clor A), clorofila B (Clor B), clorofila total (Clor T) e massa de 100 grãos (M100) da soja BRS 360 RR após cultivos de outono-inverno, no ano agrícola 2014/2015 - Dourados - MS, 2017.

\begin{tabular}{lccccc}
\hline \multicolumn{1}{c}{ Cultivos outono-inverno } & AP $(\mathrm{cm})$ & Clor A & Clor B & Clor T & M100 (g) \\
\hline Feijão-caupi & $41,0 \mathrm{a}$ & $31,8 \mathrm{a}$ & $11,6 \mathrm{a}$ & $43,4 \mathrm{a}$ & $10,1 \mathrm{bc}$ \\
Milho solteiro & $33,3 \mathrm{~b}$ & $30,3 \mathrm{~b}$ & $11,0 \mathrm{ab}$ & $41,3 \mathrm{~b}$ & $11,7 \mathrm{a}$ \\
B. ruziziensis & $41,8 \mathrm{a}$ & $30,2 \mathrm{~b}$ & $10,6 \mathrm{~b}$ & $40,8 \mathrm{bc}$ & $9,3 \mathrm{c}$ \\
Milho-B. ruziziensis & $38,7 \mathrm{a}$ & $29,0 \mathrm{c}$ & $10,5 \mathrm{~b}$ & $39,4 \mathrm{c}$ & $10,4 \mathrm{~b}$ \\
Média Geral & 38,7 & 30,3 & 10,9 & 41,2 & 10,3 \\
\hline C.V. $(\%)$ & 10,05 & 3,51 & 7,13 & 4,08 & 8,09 \\
DMS & 4,29 & 1,77 & 0,86 & 1,86 & 0,92 \\
\hline
\end{tabular}

Médias seguidas da mesma letra na coluna não diferem entre si pelo teste de Tukey $(\mathrm{p}<0,05)$.

Com relação a M100, a soja apresentou melhores resultados quando cultivada em sucessão ao milho solteiro. Para Santos et al. (2006) a sucessão de soja com milho ou sorgo podem proporcionar incrementos a cultura, mesmo havendo lenta liberação de nutrientes devido aos colmos com alto teor de lignina. A cultura do milho solteiro é uma tecnologia que pode ser considerada conservacionista, quando usada em rotação de culturas, dessa forma, podendo ocorrer acúmulo de matéria orgânica devido aos restos culturais da cultura na camada superficial do solo (SANTOS et al., 2006).

Os resultados para índice de área foliar (IAF) foram influenciados pela interação dos cultivos de outonoinverno e inoculação das bactérias avaliadas. Observouse que a maior média de IAF ocorreu na soja sem a presença de inoculante em sucessão ao milho solteiro, não diferindo-se estatisticamente da $B$. ruziziensis; dessa forma pode se inferir que a ausência do inoculante foi compensada pelo milho solteiro, pelo acúmulo de resíduos vegetais e mesmo apresentando lenta liberação de nutrientes pela alta relação $\mathrm{C} / \mathrm{N}$ (COSTA et al., 2012) ainda proporciona condições para maiores índices foliares (Tabela 2).

A inoculação somente com Bradyrhizobium japonicum e quando também houve a coinoculação dos dois grupos de bactérias as médias observadas foram estatisticamente iguais em sucessão aos quatro cultivos. De acordo com Silva et al. (2011), a inoculação ou coinoculação podem mostrar respostas contraditórias no desenvolvimento das plantas, podendo inibir ou estimular o crescimento, variando em função do nível de concentração do inóculo e do tipo de inoculação na cultura.

Com relação aos cultivos de outono-inverno, observou-se maior IAF da soja sem presença de inoculante $\left(5,4 \mathrm{~m}^{2}\right)$ no milho solteiro. De acordo com Gassen (2002) o índice de área foliar (IAF) de soja, necessário para garantir rendimentos elevados, varia entre 3,5 a 4,5 $\mathrm{m}^{2}$ para cada $\mathrm{m}^{2}$ de área de solo, ou seja, uma relação aproximada de 4:1. Valores semelhantes de
IAF foram obtidos neste tratamento, porém para os outros cultivos de outono-inverno não houve diferença estatística. Uma explicação seria a capacidade de todos os sistemas de outono-inverno proporcionarem a disponibilidade de nutrientes pela decomposição dos restos culturais. Outra hipótese seria a perda de água por evaporação ser menor no SPD formando uma barreira isolante com a camada de resíduos vegetais, diminuindo a temperatura na superfície e elevando a disponibilidade de água no solo (SALTON; MIELNICZUK, 1995). Favarin et al. (2002), explicam que o processo fotossintético depende da interceptação da luz e sua conversão em energia química, portanto, o IAF pode ser considerado um parâmetro indicativo de produtividade.

Os resultados para produtividade foram influenciados pela interação dos cultivos de outonoinverno e inoculação das bactérias avaliadas. A soja, sem a presença de inoculante e quando inoculada somente com Bradyrhizobium japonicum, apresentou superioridade quando cultivada em sucessão ao milho solteiro. O milho solteiro pode ser considerado um sistema conservacionista quando usado em rotação de culturas, tendo como características a manutenção da umidade e acúmulo de nutrientes na camada superficial do solo (SANTOS et al., 2006) (Tabela 3).

Com relação à técnica de coinoculação de Bradyrhizobium japonicum mais Azospirillum brasilense, a soja apresentou maior produtividade em sucessão ao consórcio de milho com $B$. ruziziensis, não se diferindo estatisticamente da B. ruziziensis e do milho solteiro. Bárbaro et al. (2009), estudando a técnica de coinoculação, observou que a soja obteve maior rendimento de grãos $\left(2.986 \mathrm{~kg} \mathrm{ha}^{-1}\right)$ e maior massa de mil grãos, com inoculantes a base de Azospirillum brasilense. Hungria et al. (2015), afirmam que incrementos na cultura da soja podem ser confirmados, em relação a inoculação exclusiva de Bradyrhizobium e com a coinoculação de Bradyrhizobium mais Azospirillum, podendo aumentar até $7,7 \%$ na produtividade. 
Tabela 2. Índice de área foliar (IAF) da soja BRS 360 RR sem inoculação (BRS 360 - 0), inoculada somente com Bradyrhizobium japonicum (BRS 360 - CB) e com Bradyrhizobium japonicum mais Azospirillum brasilense (BRS 360 - CB+A), no ano agrícola 2014/2015 - Dourados - MS, 2017.

\begin{tabular}{lcccc}
\hline \multirow{2}{*}{ Cultivar } & \multicolumn{3}{c}{$\mathrm{IAF}\left(\mathrm{m}^{2}\right)$} \\
\cline { 2 - 5 } & Feijão-caupi & Milho solteiro & B. ruziziensis & Consórcio milho-B. ruziziensis \\
\hline BRS 360 - 0 & $2,7 \mathrm{aB}$ & $5,4 \mathrm{aA}$ & $4,1 \mathrm{aAB}$ & $3,3 \mathrm{aB}$ \\
BRS 360 - CB & $3,4 \mathrm{aA}$ & $2,8 \mathrm{bA}$ & $3,5 \mathrm{aA}$ & $2,7 \mathrm{aA}$ \\
BRS 360 - CB+A & $3,2 \mathrm{aA}$ & $3,6 \mathrm{bA}$ & $3,2 \mathrm{aA}$ & $3,2 \mathrm{aA}$ \\
Média Geral & 4,0 & 3,9 & 3,6 & 3,0 \\
\hline C.V. (\%) & & \multicolumn{4}{c}{22,80} \\
DMS & & 1,51 & \\
\hline
\end{tabular}

Médias seguidas da mesma letra minúscula na coluna e maiúscula na linha, não diferem entre si pelo teste de Tukey (p<0,05).

Tabela 3. Produtividade (Prod. $\mathrm{kg} \mathrm{ha}^{-1}$ ) da soja BRS 360 RR sem inoculação (BRS 360 - 0), inoculada somente com Bradyrhizobium japonicum (BRS 360 - CB) e com Bradyrhizobium japonicum mais Azospirillum brasilense (BRS 360 - CB+A) no ano agrícola 2014/2015 - Dourados-MS, 2017.

\begin{tabular}{lcccc}
\hline \multirow{2}{*}{ Cultivar } & \multicolumn{3}{c}{ Prod. kg ha $^{-1}$} \\
\cline { 2 - 5 } & Feijão-caupi & Milho solteiro & B. ruziziensis & Consórcio milho-B. ruziziensis \\
\hline BRS 360 - 0 & $2.176 \mathrm{aAB}$ & $2.573 \mathrm{abA}$ & $1.983 \mathrm{aB}$ & $2.281 \mathrm{aAB}$ \\
BRS 360 - CB & $2.091 \mathrm{aB}$ & $2.737 \mathrm{aA}$ & $1.946 \mathrm{aB}$ & $2.056 \mathrm{aB}$ \\
BRS 360 - CB+A & $1.950 \mathrm{aB}$ & $2.251 \mathrm{bAB}$ & $2.168 \mathrm{aAB}$ & $2.511 \mathrm{aA}$ \\
Média Geral & 2.072 & 2.520 & 2.032 & 2.282 \\
\hline C.V. $(\%)$ & & 11,8 & \\
DMS & & 506,82 & \\
\hline Médias sequidas da mesma letra minúscula na coluna e maiúscula na linha não diferem entre si pelo teste de Tukey $(\mathrm{p}<0,05)$
\end{tabular}

Médias seguidas da mesma letra minúscula na coluna e maiúscula na linha, não diferem entre si pelo teste de Tukey (p<0,05).

Para a média geral de cada cultivo de outonoinverno, $\mathrm{o}$ milho solteiro proporcionou maior produtividade à soja $\left(2.520 \mathrm{~kg} \mathrm{ha}^{-1}\right)$, seguido do consórcio milho-B. ruziziensis $\left(2.282 \mathrm{~kg} \mathrm{ha}^{-1}\right)$, feijãocaupi $\left(2.072 \mathrm{~kg} \mathrm{ha}^{-1}\right)$ e da B. ruziziensis $\left(2.032 \mathrm{~kg} \mathrm{ha}^{-1}\right)$, independente dos tratamentos (com ou sem inoculação), mostrando que a rotação de culturas também é de grande importância para que se tenha um bom rendimento. De acordo com Pavanelli e Araújo (2009) existe uma relação importante entre inoculação e o histórico de cultivos antecessores na área; ambos podem influenciar na eficiência de inoculação à soja visto que mesmo inoculada, perderá a eficiência na inoculação pelas bactérias fixadoras de nitrogênio se não houver um sistema de rotação de culturas.

Com relação aos valores de rendimento de massa de folhas secas $\left(757 \mathrm{~kg} \mathrm{ha}^{-1}\right)$, rendimento de massa de hastes secas $\left(811 \mathrm{~kg} \mathrm{ha}^{-1}\right)$, rendimento de massa de plantas secas total $\left(1.568 \mathrm{~kg} \mathrm{ha}^{-1}\right)$ e número de grãos por planta (122), não foram influenciados pelos fatores em estudo. Os resultados coincidiram com os de Bárbaro et al. (2011) e Silva et al. (2011), onde também verificouse que a inoculação ou a coinoculação de Bradyrhizobium mais Azospirillum brasilense não influenciaram na massa seca da parte aérea das plantas e no número de grãos por planta de soja. Os autores ainda afirmam que resultados obtidos com a inoculação ou coinoculação podem mostrar respostas contraditórias, ou seja, tanto estimular como inibir a formação de massa seca total de soja, variando em função do nível de concentração do inóculo, do tipo de inoculação e a compatibilidade entre cepa diazotrófica e a cultura. Ferlini (2006), realizando 10 ensaios de campo, observaram que 8 ensaios demonstraram maior taxa de germinação, maior velocidade de emergência de plântulas e maior crescimento radicular da soja com a coinoculação de Bradyrhizobium japonicum e Azospirillum brasilense, porém ao final não foram encontradas diferenças significativas quanto aos rendimentos da parte aérea da planta; o autor ainda salienta que plantas respondem de acordo com diferentes combinações de inoculante, porém se torna necessário um histórico de inoculações às culturas antecessoras na área.

\section{Conclusões}

Ocorreram incrementos na produtividade da soja inoculada e sem inoculante quando cultivada após o milho solteiro e consórcio de milho com $B$. ruziziensis inoculada com Bradyrhizobium e Azospirillum.

São necessários mais trabalhos relacionados com a técnica de coinoculação junto aos cultivos de outonoinverno para a região de Dourados-MS.

\section{Referências Bibliográficas}

BÁRBARO, I. M.; BÁRBARO JUNIOR, L. S.; TICELLI, M.; MACHADO, P. C.; MIGUEL, F. B. Resultados preliminares da co-inoculação de Azospirillum juntamente com Bradyrhizobium em soja. Apta Regional - Pesquisa e Tecnologia, Colina-SP, v. 8, n. 2, p. 1-6, 2011. 
BÁRBARO, I. M.; MACHADO, P. C.; BÁRBARO JUNIOR, L. S.; TICELLI, M.; MIGUEL, F. B.; SILVA, J. A. A. Produtividade da soja em resposta à inoculação padrão e coinoculação. Colloquium Agrariae, Presidente Prudente-SP, v. 5, n. 1, p. 1-7, 2009.

BASHAN, Y.; DE-BASHAN, L. E.; PRABHU, S. R.; HERNANDEZ, J. P. Advances in plant growth-promoting bacterial inoculant technology: formulations and practical perspectives (1998-2013). Plant and Soil, Dordrecht, v. 1, n. 378, p. 1-33, 2014.

BUENO, A. F.; MOREIRA, A.; BALBINOT JUNIOR, A. A.; CARVALHO, C. G. P.; GAZZONI, D. L.; MARCELINOGUIMARÃES, F. C.; HENNING, F A.; NEUMAIER, N. Tecnologias de produção de soja: Região Central do Brasil 2014. Londrina-PR: Embrapa Soja, 2014. 266 p.

CASTRO, C. M.; ALVES, B. J. R.; ALMEIDA, D. L.; RIBEIRO, R. L. D. Adubação verde como fonte de nitrogênio para a cultura da berinjela em sistema orgânico. Pesquisa Agropecuária Brasileira, Brasília-DF, v. 39, n. 8, p. 779-785, 2004.

CECCON, G.; STAUT, L. A.; SAGRILO, E.; MACHADO, L. A.; NUNES, D. P.; ALVES, V. B. Legumes and forage species sole or intercropped with corn in soybean-corn succession in Midwestern Brazil. Revista Brasileira de Ciência do Solo, Viçosa-MG, v. 37, n. 1, p. 204-212, 2013.

CHIODEROLI, C. A.; MELO, L. M. M.; GRIGOLLI, P. J.; SILVA, J. O. R.; CESARIN, A. L. Consorciação de braquiárias com milho outonal em plantio direto sob pivô central. Engenharia Agrícola. Campina Grande-PB, v. 30, n. 6, p. 1101-1109, 2010.

COSTA, H. J. U.; JANUSCKIEWICZ, E. R.; OLIVEIRA, D. C.; MELO, E. S.; RUGGIERI, A. C. Massa de forragem e características morfológicas do milho e da Brachiaria brizantha cv. piatã cultivados em sistema de consórcio. ARS Veterinária, Jaboticabal-SP, v. 28, n. 2, p. 134-143, 2012.

EMBRAPA. EMPRESA BRASILEIRA DE PESQUISA AGROPECUÁRIA. Embrapa apresenta cultivares de soja para safra 2013/2014 em MS. Dourados-MS: Embrapa Agropecuária Oeste, 2013. Disponível em: https://www.embrapa.br/busca-de-noticias/-

/noticia/1471969/embrapa-apresenta-cultivares-de-soja-parasafra-20132014-em-ms-. Acesso em: 03 mai. 2017.

EMBRAPA. EMPRESA BRASILEIRA DE PESQUISA AGROPECUÁRIA. Guia Clima. Dourados-MS: EMBRAPA AGROPECUÁRIA OESTE, 2015. Disponível em: http://www.cpao.embrapa.br/clima/?lc=site/bancodados/construtor-basico. Acesso em: 14 jun. 2015.

FAVARIN, J. L.; DOURADO NETO, D.; GARCÍA, A. G.; NOVA, N. A. V.; FAVARIN, M. G. G. V. Equações para a estimativa do índice de área foliar do cafeeiro. Pesquisa Agropecuária Brasileira, Brasília-DF, v. 37, n. 6, p. 769-773, 2002.

FERLINI, H. A. Co-inoculación en soja (Glicyne max) con Bradyrhizobium japonicum y Azospirillum brasilense. Villa Clara-CUB: Engormix/Agricultura-Artículos técnicos, 2006. 2 p. (Documento 01).
FLUMIGNAN, D. L.; ALMEIDA, A. C. S.; GARCIA, R. A. Necessidade de irrigação complementar da soja na região Sul de Mato Grosso do Sul. Dourados-MS: Embrapa Agropecuária Oeste, 2015. 8 p. (Circular Técnica, 34).

FREIRE FILHO, F. R.; RIBEIRO, V. Q.; BARRETO, P. D.; SANTOS, A. A. Melhoramento genético. In: FREIRE FILHO, LIMA, J. A. A.; RIBEIRO, V. Q. Feijão-caupi: avanços tecnológicos. Brasília-DF: Embrapa Informação Tecnológica, 2005. p. 29-92.

GASSEN, D. N. O risco da mistura de herbicidas com inseticidas em milho. In: GASSEN, D. N. Informativos Técnicos Cooplantio. Passo Fundo-RS: Aldeia Norte, 2002. p. $125-128$.

HUNGRIA, M.; NOGUEIRA, M. A.; ARAUJO, R. S. Soybean Seed Co-inoculation with Bradyrhizobium spp. and Azospirillum brasilense: A New Biotechnological Tool to Improve Yield and Sustainability. American Journal of Plant Sciences, Hubei Province-China, v. 6, n. 1, p. 811-817, 2015.

KUMUDINI, S. Soybean growth and development. In: SINGH, G. The Soybean: botany, productions and uses. India-IND, 2010. p. 48-73.

LOCATELLI, V. E. R.; MEDEIROS, R. D.; SMIDERLE, O. J.; ALBUQUERQUE, J. A. A.; ARAÚJO, W. F. Desenvolvimento vegetativo de cultivares de feijão-caupi sob lâminas de irrigação no Cerrado Roraimense. Revista Irriga, Botucatu-SP, v. 1, n. 1, p. 28-39, 2016.

MERCANTE, F. M.; HUNGRIA, M.; MENDES, I. C.; JÚNIOR, F. B. R. Estratégias para aumentar a eficiência de inoculantes microbianos na cultura da soja. Dourados-MS: Embrapa Agropecuária Oeste, 2011. 4 p. (Documento, 169).

MYLONA, P.; PAWLOSKI, K.; BISSELING, T. Symbiotic nitrogen fixation. The Plant Cell, Waterbury-VT, v. 7, n. 1, p. 869-885, 1995.

OLIVEIRA, P.; NASCENTE, A. S.; KLUTHCOUSKI, J. Soybean growth and yield under cover crops. Revista Ceres, Viçosa-MG, v. 60, n. 2, p. 249-256, 2013.

PADOVAN, M. P.; MOTTA, I. S.; CARNEIRO, L. F.; MOITINHO, M. R.; SALOMÃO, G. B.; RECALDE, K. M. G. Pré-cultivo de adubos verdes ao milho em agroecossistema submetido a manejo ecológico no cone Sul de Mato Grosso do Sul. Revista Brasileira de Agroecologia, Pelotas-RS, v. 8, n. 3, p. 3-11, 2013.

PAVANELLI, L. E.; ARAÚJO, F. F. Fixação biológico de nitrogênio em soja em solos cultivados com pastagens e culturas anuais do oeste paulista. Bioscience Journal, Uberlândia-MG, v. 25, n. 1, p. 21-29, 2009.

SALTON, J. C.; MIELNICZUK, J. Relações entre sistemas de preparo, temperatura e umidade de um Podzólico VermelhoEscuro de Eldorado do Sul (RS). Revista Brasileira de Ciências do Solo, Viçosa-MG, v. 19, n. 1, p. 313-319, 1995.

SANTOS, H. G.; JACOMINE, P. K. T.; ANJOS, L. H. C.; OLIVEIRA, V. A.; LUMBRERAS, J. F.; COELHO, M. R.; ALMEIDA, J. A.; CUNHA, T. J. F.; OLIVEIRA, J. B. Sistema brasileiro de classificação de solos. 3. ed. Rio de Janeiro-RJ: Embrapa Solos, 2013. 353 p. 
SANTOS, H. P.; LHAMBY, J. C. B.; SPERA, S. T.

Rendimento de grãos de soja em função de diferentes sistemas de manejo de solo e de rotação de culturas. Ciência Rural, Santa Maria-RS, v. 36, n. 1, p. 21-29, 2006.
SILVA, A. F.; CARVALHO, M. A. C.; SCHONINGER, E. L.; MONTEIRO, S.; CAIONE, G.; SANTOS, P. A. Doses de inoculante e nitrogênio na semeadura da soja em área de primeiro cultivo. Bioscience Journal, Uberlândia-MG, v. 27, n. 3, p. 404-412, 2011. 